\title{
Future US megadroughts set to be the worst in 1,000 years
}

\section{Southwest and Great Plains expected to see to significantly drier conditions by end of century.}

\section{Alexandra Witze}

12 February 2015

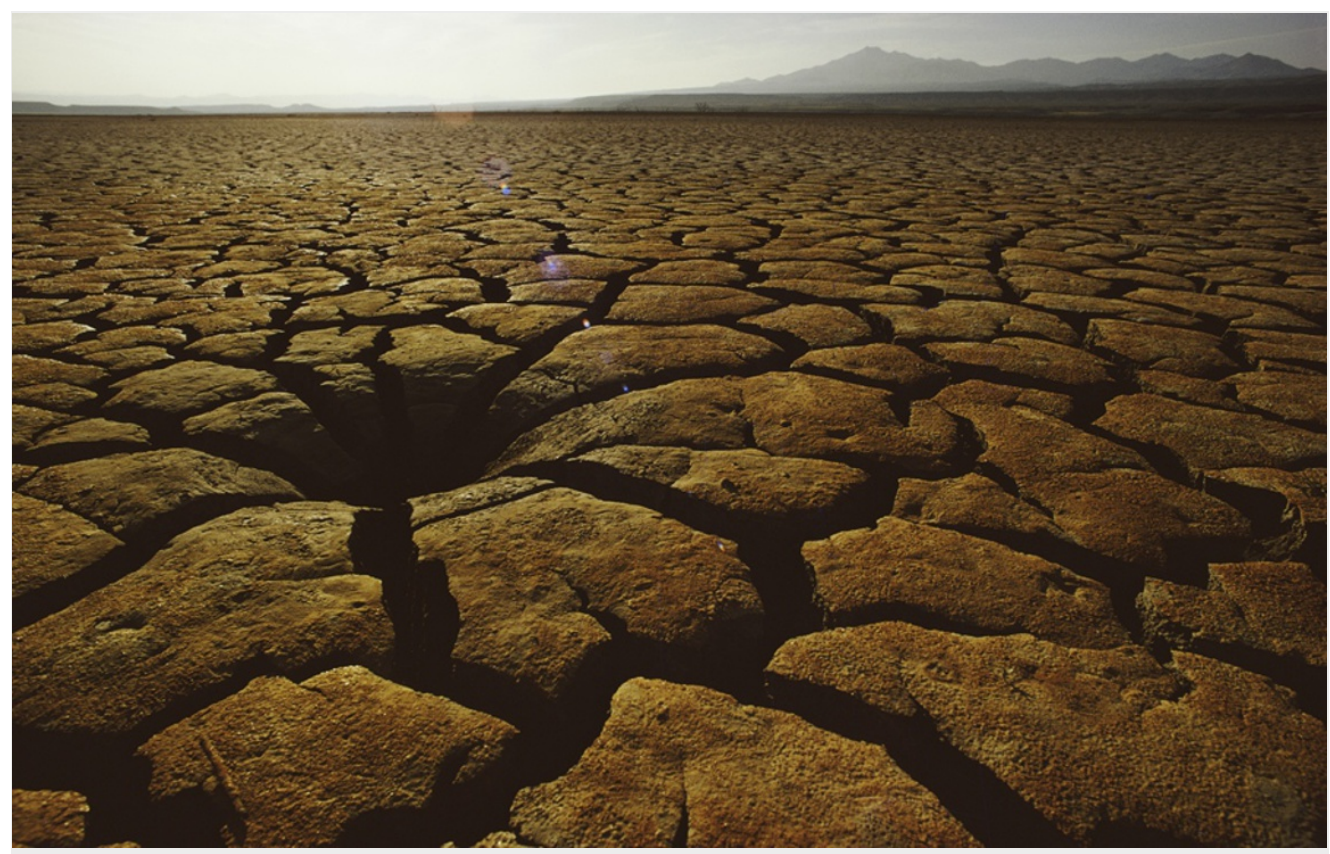

Lamy Dale Gordon/Getty

Climate models suggest that large swathes of the United States will shift to a much drier climate in coming decades.

Decades-long droughts are likely to ravage the US Southwest and Great Plains within the next century, a study suggests. This drying could be worse than any other in the past 1,000 years, including a 'megadrought' seven centuries ago that helped drive an ancient civilization to collapse.

The work, published on 12 February in Science Advances ${ }^{1}$, is among the first to rigorously compare the climate record of the deep past with long-term projections of today's warming climate.

"These future droughts are not only going to be bad compared to what we've experienced over the historical period, but also really bad compared to the past millennium," says Benjamin Cook, a drought researcher at NASA's Goddard Institute for Space Studies in New York City, who led the work. "It's going to be a pretty much fundamental shift."

Much of North America has a long and detailed climate history, thanks to tree rings that preserve records of temperature and rainfall. Many scientists have used these to piece together the story of decades-long droughts, like one that gripped the US Southwest in the thirteenth century and probably contributed to the disappearance of ancient Pueblo peoples. Others have used global climate models to study the region's future, and found that it may already be transitioning to a fundamentally drier state ${ }^{2}$.

Cook's team aimed to bridge past and present. The scientists compared 1,000 years of North American climate history with future projections from 17 different climate models - "as many as we could get our hands on that gave us the data we needed", Cook says.

\section{Drying out}

Among other metrics, the researchers looked at a measure known as the Palmer Drought Severity Index, which is an indicator of soil moisture. Some scientists criticize the Palmer index because it can overestimate future drying if it is calculated on the basis of temperature projections alone. To get around this problem, Cook's team used a different method of calculating the index, one that incorporates humidity and energy from sunlight. 
Kevin Anchukaitis, a palaeoclimatologist at the Woods Hole Oceanographic Institution in Massachusetts, says that the revised method gives a much more accurate projection of how dry things will really get. "This is the first convincing demonstration l've seen that it is both possible to seamlessly connect past, present and future, and to then be confident that they are on comparable scales," he says.

Cook's team modelled conditions through to the end of the twenty-first century, using both a scenario that assumes that greenhousegas emissions will continue on current trends — staying relatively high — and a more moderate scenario that would require major emissions cuts. Models run using both scenarios projected significant dryness between the years 2050 and 2099. These droughts would persist for many years and be even worse than the medieval megadroughts, says Cook.

California is currently in the grip of a drought that has lasted for several years, and the Southwest has been in another for more than a decade. "Imagine those droughts lasting 20, 30, maybe even 50 years - that gives you a sense for what the future droughts will look like," says Cook. "They will be very strongly amplified by anthropogenic warming." Tens of millions of people live in the regions at risk.

The next step is to work out exactly when this shift to a drier baseline climate might come. Cook and his team want to use models to tease out when the effects of human-driven warming might start to exceed natural climate variability.

Nature | doi:10.1038/nature.2015.16916

\section{References}

1. Cook, B. I., Ault, T. R. \& Smerdon, J. E. Sci. Adv. 1, e1400082 (2015).

2. Seager, R. et al. Science 316, 1181-1184 (2007). 